\title{
UM OLHAR SOBRE A APRENDIZAGEM DISCENTE NO ENSINO REMOTO EMERGENCIAL
}

\section{Carlos Henrique da Costa Barreto'; Graziela Frainer Knoll²; Taís Steffenello Ghisleni ${ }^{3}$}

\section{RESUMO}

Este é um estudo da Comunicação Social desenvolvido na Universidade Franciscana na temática de educação em tempos de pandemia. Teve por objetivo geral construir um olhar sobre o processo de aprendizagem discente no atual Ensino Remoto Emergencial (ERE). Tal perspectiva é apresentada a partir de análise em dois pontos: 1) considerações iniciais acerca da migração discente ao ERE; e 2) observações sobre usos e empregos da tecnologia por esse público, nesse formato de ensino. O estudo tem natureza qualitativa com caráter exploratório e descritivo. De resultados, observamos as primeiras mudanças, dificuldades e desafios discentes surgidas logo em função da troca de modelos presenciais para remoto, ao que também foram assim identificadas diferentes tecnologias, estratégias e recursos da Era Digital e das Tecnologias de Informação e Comunicação que influenciaram no processo e guiaram esses discentes em sua adaptação ao ERE, não obstante, também seu processo de aprendizagem nesse novo formato.

Palavras-chave: Educação; Estratégias; Estudantes; Pandemia; Adaptação.

Eixo Temático 2: Educação, Cultura e Comunicação (ECC).

\section{INTRODUÇÃO}

A Covid-2019 afetou e modificou os mais diversos setores da nossa vida no mundo contemporâneo. Domingues (2021) introduz uma visão sobre as crises e problemas causados na sociedade e na Comunicação pela desinformação acerca da pandemia - o que a autora denomina como Infodemia. Embora o estudo não esteja de todo relacionado à nossa temática, podemos apontar dele um ponto chave: é necessária compreensão todas as situações e dimensões que a pandemia afeta para que só então seja viável de trabalhá-la.

\footnotetext{
${ }^{1}$ Autor - Universidade Franciscana; email: carloshcb123@gmail.com

${ }^{2}$ Coorientadora - Universidade Franciscana; email: grazi.fknoll@gmail.com

${ }^{3}$ Orientadora - Universidade Franciscana; email: taisghisleni@yahoo.com.br
} 
Ghisleni, Barreto e Becker (2020, p. 3), no meio educacional, observam que "o cenário [...] vem enfrentando adversidades [...] na qual o distanciamento social implicou no principal fator de mudança": a adoção do modelo de Ensino Remoto Emergencial (ERE) por diversas instituições de ensino a fim de manter a educação com respeito às normas sanitárias. Na temática de ensino em tempos de pandemia, a fala dos autores surge de uma pesquisa da Comunicação Social desenvolvida na Universidade Franciscana (UFN) de Santa Maria, Rio Grande do Sul, em dois momentos: um estudo bibliográfico exploratório produzido levantando possibilidades e desafios em se lecionar pelo ERE; e, após, um estudo de campo na própria Instituição com os cursos de Publicidade e Propaganda e de Jornalismo para compreender o ERE em suas visões.

Feitosa et. al. (2020, p. 3) ressalta que "sair de um ensino presencial movido por uma interação física entre público e infraestrutura física disponível e submeter-se ao ensino remoto é um desafio para alunos e professores". Disso vemos que um olhar científico do panorama de Ensino Remoto Emergencial não pode se restringir unicamente ao público docente, mas deve vir pelo amplo. Rabaiolli e Hansen (2020, p. 179) também refletiram sobre questões acerca do tema: "Como estão os estudantes [...] diante do ensino remoto? Pela pesquisa não há respostas discentes, mas a percepção docente nos permite problematizar" e reconhecem uma "premência de pesquisas com estudantes para avaliar a relação estudantil com o ensino remoto na área." (RABIOLLI; HANSEN, 2020, p. 179).

Assim, o presente estudo compõe a primeira parte de um novo projeto de pesquisa $^{4}$ iniciado na UFN que dá seguimento ao anterior. Busca agora a perspectiva discente no ERE, para construir um diálogo cruzando teorias, visões e debates entre professores e alunos: temos por objetivo geral construir um olhar sobre o processo de aprendizagem discente pelo ERE frente às diversas mudanças impostas da pandemia. Isto, a partir de dois pontos específicos: 1) contextualizar as questões iniciais aos estudantes em função da troca dos modelos e estruturas de ensino presenciais para o ERE; e 2) mapear as formas de interação com a

\footnotetext{
4 Projeto de Pesquisa Probic FAPERGS intitulado "Os multiprocessos de ensino-aprendizagem discente na Comunicação Social pelo Ensino Remoto em tempos de pandemia", aprovado na Universidade Franciscana pelo Edital 15/2021.
} 
tecnologia e demais recursos utilizados pelo discente para alcançar uma adaptação ao novo formato.

Nosso propósito nesse momento é elaborar uma base teórica para a próxima produção do projeto em que trabalharemos junto aos mesmos cursos da Comunicação Social - como no anterior - mas coletando a visão de seus estudantes. Feitosa et al. (2020, p. 7), novamente, apontam que toda a estrutura tradicional de ensino "foi rompida sem a escolha de professores e alunos" em vista da pandemia - ao que o mesmo se passou pela UFN. Então construímos esse levantamento inicial sobre os diversos fatores relativos ao público discente no ERE a partir de pesquisas e bibliografias para compreendermos se as mesmas situações / dimensões se aplicam na UFN, se existem novos fatores, e de que forma podem ser trabalhados - fechando assim a ideia de Domingues (2021).

\section{METODOLOGIA}

Este é um estudo de natureza qualitativa descritiva, conforme Michel (2009, p. 44) buscando "verificar e explicar problemas, fatos ou fenômenos da vida real [...] fazendo relações, conexões à luz da influência que o ambiente exerce sobre eles": observamos como o discente se relaciona com o Ensino Remoto Emergencial e, construindo nossa percepção, como o seu processo de aprendizagem é afetado pela pandemia e suas questões.

A escolha de dois objetivos específicos para estruturar nosso desenvolvimento parte dos resultados obtidos em momento anterior, Ghisleni, Barreto e Becker (2020) e dos dois grupos de autores que o nortearam: Moreira, Henriques e Barros (2020) e Petermann et al. (2020). O primeiro, sobre como docentes naturalizados no ensino presencial poderiam adaptar suas práticas ao ERE e, apresentando "os princípios básicos para o design de um ambiente online, relacionado à organização, seleção de recursos, preparação e avaliação [...] de aprendizagem" (MOREIRA; HENRIQUES; BARROS, 2020, p. 351); O segundo, um estudo - também na área da Comunicação - que avaliava o ensino de Publicidade e Propaganda na pandemia, com olhares sobre as tecnologias empregadas, as dificuldades sentidas, e as estratégias de adaptação docente. Desses trabalhos 
pudemos estabelecer uma relação de cada autor com olhar ao público discente, e nossa análise foi desenvolvida sob dois pontos: suas principais questões metodológicas no ERE, essas advindas da abrupta troca de formatos; e as principais estratégias e/ou tecnologias empregadas por eles para alcançar garantir uma adaptação efetiva;

Assim, este estudo inicial surge essencialmente sob bibliografias atuais, em temática de pandemia, abordando questões discentes que ajudam a compor o olhar buscado no atual projeto - o que também lhe confere um caráter de estudo exploratório, dada sua finalidade de "desenvolver, esclarecer e modificar conceitos [...] com vista na formulação de problemas mais precisos ou hipóteses pesquisáveis para estudos posteriores" (GIL, 1989, p. 44). Nos próximos tópicos, segue nosso desenvolvimento construído: um olhar sobre a aprendizagem discente no Ensino Remoto Emergencial considerando sua introdução no modelo até a adaptação tecnológica conquistada.

\section{APRENDIZAGEM DISCENTE NO ERE: Da introdução à uma adaptação metodológica e tecnológica}

\subsection{Público discente no ERE: considerações iniciais}

Começamos pela observação de Lima et al. (2020, p. 615) de que "para muitos alunos, o ensino remoto representa um dilema e desafio a serem suplantados, pois grande parte são considerados imigrantes digitais [...]". Junto a Sahu (2020) sobre Covid-2019 e modelos de ensino, expõe-se a realidade de que estudantes brasileiros ainda são na maioria naturalizados no sistema de ensino presencial, em sala de aula, com trocas alunos-professores e alunos-alunos simultânea e dinamicamente correndo nesse mesmo ambiente (LIMA et al., 2020). Daí surge o conceito de "imigrantes digitais" e fica claro como as primeiras questões do ERE em perspectiva discente partem dessa abrupta troca de modelos.

Joye, Moreira e Rocha (2020) apontam que o ERE possui a característica de sincronismo digital: as aulas ocorrem em tempo real e, por isso, estão sempre ancoradas numa plataforma de vídeo ou sistema que permita este funcionamento. Ghisleni, Barreto e Becker (2020, p. 302) o descrevem como uma espécie de "sala 
de aula remota, adaptada a rotina domiciliar". Contudo, surge ao discente, aí, uma problemática: o uso e a necessidade da tecnologia. Lima et al. (2020) verifica que mais da metade dos domicílios brasileiros não possuem acesso à um computador (desktop ou notebook) e mais de um terço do grande grupo não dispõe do acesso à internet - o que se torna o primeiro obstáculo desses para frequentar o ensino remoto.

Artigas (2017), anterior ao cenário pandêmico, desenvolve um estudo sobre Ensino a Distância (EAD) no qual observamos uma realidade refletida diretamente hoje entre os discentes do ERE: muitos alunos apresentam dificuldade em conduzir o tempo livre ou disponível para as atividades no ensino não presencial - fazendo com que mesmo aqueles que possuam a estrutura necessária acabem por não frequentar as aulas com a mesma assiduidade e disciplina que apresentariam no ensino tradicional. Isso pode atrasar sua trajetória no ensino, o ritmo das aulas, dos conteúdos, das atividades e de maneira geral comprometer todo o processo de aprendizado fragmentando-o em momentos esparsos (ARTIGAS, 2017); (GHISLENI; BARRETO; BECKER, 2020).

E por essa razão, as taxas de evasão ao ERE foram altas e o público discente sentiu diversas resistências até se encaixar num processo de aprendizagem estabelecido nessas dinâmicas (NERI; OSORIO, 2021) - sobretudo ao início da transição, de março ao final do primeiro semestre de 2020 onde "as mudanças no sistema educacional tiveram de ser realizadas rapidamente [...] de um dia para o outro" (RONDINI; PEDRO; DUARTE, 2020, p. 43) e todos os métodos dos atores acadêmicos eram experimentais ou exploratórios dentro do novo formato. Porém, dos trabalhos analisados, também foi percebido que, passados os momentos iniciais da pandemia, o público discente em geral conquistou um ritmo mais promissor no ERE e aparentemente se adaptou às mudanças tal como os docentes.

Em primeiras reflexões nessa ideia, Martins e Almeida (2020), observaram que os discentes adquiriram relativa preferência - e até gosto - pela rotina domiciliar aliada ao ensino. Perceberam que os alunos realmente desenvolveram afinidade pelas videoaulas "potencializando os debates, o pensamento crítico, a criatividade, o fazer conjunto, as reflexões a respeito da experiência social [...] (MARTINS; 
ALMEIDA, 2020, p. 223) que se aliaram a outras questões como a comodidade e o conforto de aulas em casa (PIFFERO et al., 2020). No entanto, esclarecem que esta conquista só foi possível após percorrido quase um ano de desafios, tentativas e adaptações.

Por conseguinte, temos a perspectiva de um público, além de "imigrantedigital", também "nativo-presencial": um público que se naturalizou com a estrutura clássica do ensino em sala de aula, mas que enfrentou os desafios das mudanças metodológicas com aulas virtuais, aprendizados por novas formas de comunicação, e uma ressignificação de seus próprios aparelhos e ambientes e pessoais como "extensões" diretas da academia. É válido crer que o discente percorreu uma trajetória como os próprios docentes, tanto de desafios de adaptação quanto de oportunidades no novo formato. No próximo tópico, discutimos essa adaptação conforme principais interações tecnológicas e demais recursos compreendidos na jornada discente de aprendizado pelo ERE.

\subsection{Tecnologias, estratégias e recursos de adaptação}

Começando com tecnologias, Martins e Almeida (2020, p. 219) resumem um menu de experimentações aos alunos no ERE: "vídeos, conferências on-line, mensagens, lives, áudios, imagens e sons, tudo junto e misturado". Em outras palavras, vê-se um ensino híbrido com metodologias ativas que incentivam o próprio discente a desenvolver autonomia, criatividade e a disciplina necessária para se adaptar à situação. Moran (2018) já inferia que a hibridização do ensino e a inserção das Tecnologias da Informação e da Comunicação (TIC) configuram soluções dinâmicas para o aprendizado de hoje colocando o estudante em papel principal do processo.

Desse modo, na educação em tempos de pandemia, "membros e atores de todos os setores enxergam a necessidade de se adaptar e contornar as adversidades com as ferramentas e tecnologias que dispõem" (GHISLENI; BARRETO; BECKER, 2020, p. 307) e, para Silva, Souza e Menezes (2020, p. 300) "diversos trabalhos pesquisam e relatam a aceitação [...] e o necessário uso das tecnologias na educação [...]". Porém, devemos considerar que no ensino tradicional, é comum que muitas instituições disponibilizem um espaço específico 
aos alunos com as tecnologias necessárias (equipamentos, softwares e demais recursos) para uma execução completa das atividades e trabalhos. Já, no ERE, o cenário e as disponibilidades são bem diferentes: mesmo aqueles alunos que possuem um desktop, um acesso à internet para frequentar as aulas, dentre outros itens, é fato que por muitos não dispõem dos itens específicos para a execução total das atividades, conforme verificam Avelino e Mendes (2020), como softwares, equipamentos, apps ou outros recursos.

Por isso, observamos uma "aprendizagem discente inventiva", compreendida por interações tecnológicas e emprego de diversas alternativas para uma adaptação. Conforme mapeamento de Santos et al. (2020), o uso de plataformas de videochamadas, ambientes virtuais e repositório de arquivos formam a base - e primeira adaptação - para todo estudante do ERE; Google Meets, Microsoft Teams, Zoom, Skype, Jitsi Meets, ambientes virtuais como Moodle, Moodle Classes, ou até recursos mais cotidianos como Youtube, lives no Instagram e serviços de nuvem (Drive, Dropbox, Evernote, etc) são apenas alguns dos vários recursos nesse processo, que podemos inferir (WATANABE et al., 2020).

Assim, fica claro que as Tecnologias da Informação e Comunicação (TIC) (MORAN, 2018) ganham destaque no ERE. Outros autores, como Carvalho et al. (2021, p. 5), concordam na importância do professor conceber a interação digital com alunos, enxergam possibilidades e ainda vão além: reconhecem que "o uso de recursos digitais no ensino não é uma discussão recente [...]" e que a pandemia impulsionou essa necessidade. Os autores desenvolveram um manual completo com apresentação/tutorial de utilização de diversos recursos digitais empregáveis ao ERE e ao público discente, para dinamizar o processo de aprendizagem. Em destaque, ferramentas e Apps para o trabalho com imagens e audiovisuais como, por exemplo, o Screencastify, InShot, Animaker 2.0, Tooncast, Plotagon, Padlets, dentre outros - todos gratuitos - e até as redes sociais Whatsapp, Facebook, Telegram e Instagram - num emprego totalmente voltado à educação (CARVALHO et al., 2021).

Silva, Souza e Menezes (2020, p. 306) também observam que "é importante analisar a satisfação dos discentes para com o uso das tecnologias nesse período 
de isolamento e sua influência na aprendizagem" - assim como as maneiras que são abordados cada momento das aulas. Propostas como essas dinamizam o ensino, tornam-no um processo mais agradável ao discente, utilizam uma linguagem digital à ele mais familiarizada e também respondem a problemática da utilização de recursos específicos pelos discentes: aqueles que não dispõem das mesmas ferramentas ofertadas pela instituição de ensino dispõem, então, de uma ampla gama de recursos livres e gratuitos na própria web que podem ser usados ao mesmo fim, além de impulsionar sua adaptação ao ERE com o uso da criatividade.

Não obstante, sobre "criatividade", pelos destaques de Santos (2020), o ERE também proporcionou aos discentes a experimentação de duas metodologias ativas: $1^{a}$ ) a Sala de Aula Invertida (flipped classroom), onde o material é disponibilizado todo "num ambiente virtual de aprendizagem para que os alunos possam ter acesso ao conteúdo e realizar uma certa tarefa durante o encontro na aula remota" (SANTOS, 2020, p. 6) ou mesmo "ministrar" a matéria aos colegas conforme seu aprendizado, enquanto também é avaliado pelo professor; e $2^{a}$ ) a Gamificação - que consiste na "utilização de táticas ou elementos relativos à games, para engajar pessoas - neste caso, os alunos - visando atingir objetivos ou resolver problemas através de formas dinâmicas e eficientes”, como explicam Barreto, Becker e Ghisleni (2019, p. 11).

É interessante uma relação: Barreto, Becker e Ghisleni (2019), sobre Gamificação, descrevem a chamada Educação 3.0, um modelo caracterizado pela inserção tecnológica de quaisquer recursos relativos à Era Digital ao processo de aprendizado na escola, tanto para o professor quanto (principalmente) para os estudantes - que desenvolvem papeis de protagonismos em seus processo de aprendizagem. Nesse sentido, no ERE, considerando aliança desempenhada entre o público discente com todos esses recursos debatidos, podemos reconhecer que o próprio modelo é, em si, uma extensa prática da Educação 3.0: não obstante, um amplo conjunto de interações tecnológicas e estratégias de adaptação.

Assim, concluindo de Costa et al. (2020, p. 18) "é possível verificar as inúmeras possibilidades de aplicações de diferentes metodologias de ensino durante esse período" assim como a efetividade e os resultados que cada uma promove 
quando inserida em determinada situação. $E$ pela construção desse desenvolvimento, fica clara a compreensão de que as Tecnologias da Informação e da Comunicação, da Era Digital e da visão de ensino da Educação 3.0 - juntamente das metodologias ativas de Moran (2018) - são alternativas dos discentes para promover seu processo de aprendizagem durante a pandemia, o que pode permanecer ainda para muito além: como ensinamentos de uso no próprio ensino presencial, passada a pandemia.

\section{CONSIDERAÇÕES FINAIS}

Construímos um olhar sobre o processo de aprendizagem discente no ERE pautado em desafios de adaptação essencialmente surgidos devido à troca de modelos: um público naturalizado no ensino presencial que subitamente se viu em migração para o novo formato decorrente da pandemia. Observamos os primeiros obstáculos a partir da necessidade tecnológica que o modelo traz por equipamentos (desktops, aparelhos de celular, etc), um acesso estável à internet, uma relativa estrutura domiciliar (ou no cômodo de frequência às aulas) que permita a estabilidade e permanência do discente nas aulas, e mais uma série de domínios prévio sobre linguagens digitais, plataformas de acesso às aulas e outros recursos específicos para o trabalho - itens cuja disponibilidade, evidentemente, não é possuída por boa parte do público discente no cenário educacional brasileiro.

Mas observam-se, apesar dos desafios, também as oportunidades de crescimento encontradas pelos próprios discentes em recursos gratuitos e acessíveis da web, no domínio de novas ferramentas com trabalhos em multiformatos (vídeo, textos, áudios, imagens, etc), em oportunidades de uso das Tecnologias da Informação e da Comunicação e, principalmente, na experimentação em metodologias alternativas, ativas e dinâmicas - como as práticas da Gamificação, da Educação 3.0, ou da Sala de Aula Invertida - que ressignificam seu papel na trajetória de aprendizado colocando-os como protagonistas nesse processo.

Por conseguinte, tendo se construído esta base teórica dentro do atual projeto de pesquisa - Os multiprocessos de ensino-aprendizagem discente na 
Comunicação Social pelo Ensino Remoto em tempos de pandemia - avançamos agora para a próxima etapa à se desenvolver na Universidade Franciscana com o corpo discente da Comunicação Social, onde se produz este estudo, para cruzar os dados aqui coletados e investigar se a mesma realidade se passa em nosso universo acadêmico para compreendermos - conforme aqui também construído que estratégias ou metodologias estão sendo adotadas pelos discentes para superar o momento em contornar as adversidades impostas pelo Ensino Remoto Emergencial.

\section{REFERÊNCIAS}

ARTIGAS, N. A. S. Análise documental das dificuldades apresentadas no ensino de educação à distância. EDUCERE - XIV Congresso Nacional de Educação, 2017.

AVELINO, W. F.; MENDES, J. G. A realidade da educação brasileira a partir da COVID-19. Boletim de Conjuntura (BOCA), v. 2, n. 5, p. 56-62, 2020.

BARRETO, C. H. da C.; BECKER, E. L. S.; GHISLENI, T. S. Gamificação: uma prática da educação 3.0. Research, Society and Development, v. 8, n. 4, p. e984942, 2019.

CARVALHO, L. dos S.; FONSECA, A. V.; COSTA, F. W. de L.; MELO, M. de S. Ensino remoto emergencial: Proposições e tutoriais para o uso de recursos digitais em aulas remotas. 1 ed. Natal: EDUFRN, 2021.

COSTA, T. G.; GIESTA, J. P.; NETO, C. A. O uso das tecnologias de informação e comunicação como facilitadoras do ensino remoto emergencial no contexto epidêmico da covid-19. Holos, v. 3, p. 1-24, 2021.

DOMINGUES, L. Infodemia: uma ameaça à saúde pública global durante e após a pandemia de Covid-19. Revista Eletrônica de Comunicação, Informação e Inovação em Saúde, v. 15, n. 1, 2021.

FEITOSA, M. C; MOURA, P. S.; RAMOS, M. do S. F. R.; LAVOR, O. P. Ensino Remoto: O que Pensam os Alunos e Professores? In: Anais do V Congresso sobre Tecnologias na Educação. SBC, 2020. p. 60-68.

GHISLENI, T. S.; BARRETO, C. H. da C.; BECKER, E. L. S. Educação em tempos de pandemia: a migração do ensino para o formato não presencial como um cenário de desafios e possibilidades. Disciplinarum Scientia | Ciências Humanas, v. 21, n. 2, p. 297-311, 2020. 
GIL, A. C. Métodos e técnicas de pesquisa social. 2. ed. São Paulo: Atlas S.A, 1989.

JOYE, C.; MOREIRA, M. M.; ROCHA, S. S. D. Educação a Distância ou Atividade Educacional Remota Emergencial: em busca do elo perdido da educação escolar em tempos de COVID-19. Research, Society and Development, v. 9, n. 7, p. e521974299-e521974299, 2020.

LIMA, A. C.; FREITA, J. O. PEREIRA, L. de A. S. R.; SILVA, V. G.; COELHO, M. M. P.; PEIXOTO, T. M. P.; ANDRADE, J. N. A.; MUSSE, J. de O. Desafios da aprendizagem remota por estudantes universitários no contexto da Covid-19. Revista de Divulgação Científica Sena Aires, v. 9, p. 610-617, 2020.

MARTINS, V; ALMEIDA, J. Educação em tempos de pandemia no Brasil: saberes fazeres escolares em exposição nas redes. Revista Docência e Cibercultura, v. 4, n. 2, p. 215-224, 2020.

MICHEL, M. H. Metodologia e pesquisa científica em Ciências Sociais. 2.ed. São Paulo: Atlas, 2009.

MORAN, J. Metodologias ativas para uma aprendizagem mais profunda. Metodologias ativas para uma educação inovadora: uma abordagem teóricoprática. Porto Alegre: Penso, p. 25/02, 2018.

MOREIRA, J. A.; HENRIQUES, S.; BARROS, D. M. V. Transitando de um Ensino Remoto emergencial para uma educação digital em rede, em tempos de pandemia. Dialogia, p. 351-364, 2020.

NERI, M.; OSORIO, M. C. Evasão escolar e jornada remota na pandemia. Revista NECAT-Revista do Núcleo de Estudos de Economia Catarinense, v. 10, n. 19, p. 28-55, 2021.

PETERMANN, J.; CORREA, R. S.; SCHUCH, L. A.; CURCEL, P. H. S. Relatório produzido pelo Grupo IEP - Inovação no Ensino de Publicidade, 2020. Disponível em https://a3206998-0117-4487-bafcc62fc921a86a.filesusr.com/ugd/bb9c7e_99434b4c2cfd4ca0a05b8b92e3fa59d9.pdf. Acesso em 03/04/2020.

PIFFERO, E. de L. F.; COELHO, C. P.; SOARES, R. G.; ROEHRS, R. Um novo contexto, uma nova forma de ensinar: Metodologias ativas em aulas remotas. Revista de Estudos e Pesquisas sobre Ensino Tecnológico (EDUCITEC), v. 6, p. e142020-e142020, 2020.

RABAIOLLI, J.; HANSEN, F. Experiências em ensino remoto de Publicidade e Propaganda na pandemia da Covid-19. Comunicação \& Educação, v. 25, n. 2, p. 169-183, 2020. 
RONDINI, C. A.; PEDRO, K. M.; DUARTE, C. dos S. Pandemia do Covid-19 e o ensino remoto emergencial: Mudanças na práxis docente. Interfaces CientíficasEducação, v. 10, n. 1, p. 41-57, 2020.

SAHU, P. Fechamento de universidades por doença coronavírus 2019 (COVID-19): impacto na educação e saúde mental de alunos e professores. Cureus, v. 12, n. 4, 2020.

SANTOS, V. A. dos.; DANTAS, V. R.; GONÇALVES, A. B. V.; HOLANDA, B. M. W. de.; BARBOSA, A. de A. G. O uso das ferramentas digitais no ensino remoto acadêmico: Desafios e oportunidades na perspectiva docente. In: Proceedings of the VII Congresso Nacional, de Educacao, Conedu, Edição Online. 2020. p. 15-17.

SILVA, A. C. O.; SOUSA, S. de A. S.; MENEZES, J. B. F. de. O ensino remoto na percepção discente: desafios e benefícios. Dialogia, n. 36, p. 298-315, 2020.

WATANABE, F. Y; MOREIRA, R. F. C.; SAY, K. G.;BELEZA, A. C. S.; CONTINI, A. A.; TAKASHI, A. C. M.; ANTONIALLI, A. I. S.; HELMER, E. A.; GONÇALVES, F. G. $P$. Formação docente me metodologias ativas e o uso de tecnologias digitais de informação e comunicação (TDIC) no ensino remoto emergencial. In: V Congresso Internacional de Educação e Tecnologias/Encontro de Pesquisadores em Educação a Distância (CIET:EnPED), 2020, São Carlos. Anais. São Carlos, 2020. 